Síntese - Rev. de Filosofia

v. 29 N. 95 (2002): 397-424

\title{
PRAGMATISMO E CRÍTICA DA SUBJETIVIDADE: PEIRCE CONTRA O “ESPÍRITO DO CARTESIANISMO"1
}

Waldomiro José da Silva Filho

$\mathrm{UFBA}$

Resumo: Este artigo discute como Charles S. Peirce refuta a idéia de uma fundamentação primeira da metafísica e da epistemologia a partir da concepção cartesiana de subjetividade. Com a "crítica negativa" à subjetividade (imediatidade, sense data, percepção interna, introspecção, intuição), Peirce fundou as bases do pragmatismo vindouro. Aqui serão desenvolvidos os seguintes temas: a) a rejeição da intuição, b) a crítica ao "espírito do cartesianismo" e c) o problema da "terapia das idéias", assim como aparecem em "Questions Concerning Certain Faculties Claimed for Man" e "Some Consequences of Four Incapacities" (1868), "The Fixation of Belief" (1877) e "How to Make Our Ideas Clear" (1878).

Palavras-chave: Cartesianismo, Intuição, Peirce, Pragmatismo, Subjetividade.

Abstract: This article discusses how Charles S. Peirce refutes the idea of a metaphysical and epistemological foundations from the Cartesian conception of subjectivity. With a "negative criticism" to subjectivity (immediacy, sense data, internal perception, introspection and intuition), Peirce founded the basis for the then future philosophy of pragmatism. Here some themes will be developed: a) intuitionism refuted, b) the

\footnotetext{
${ }^{1}$ Agradeço a leitura atenta e as sugestões do Prof. Floyd Merrell (Purdue University) e o incentivo do Programa de Apoio à Instalação de Doutores no Estado da Bahia (PRODOC do CADCT/UFBA/ FAPEX).
} 
criticism of the "cartesian spirit" and c) the problem of "a therapy of ideas" as it appears in "Questions Concerning Certain Faculties Claimed for Man" and "Some Consequences of Four Incapacities" (1868), "The Fixation of Belief" (1877) and "How to Make Our Ideas Clear" (1878).

Key words: Cartesianism, Intuition, Peirce, Pragmatism, Subjectivity.

"Starting with Descartes, epistemology has been almost entirely based on first person knowledge. We must begin, according to the usual story, with what is most certain: knowledge of our own sensations and thoughts."

Donald DAVIDSON, "Epistemology Externalized", 1991.

$\mathrm{N}$ este artigo, pretendo discutir como Charles S. Peirce, ao seu modo, compreendeu e refutou a idéia de uma fundamentação primeira da metafísica e da epistemologia oferecida pela concepção cartesiana de subjetividade e, ao fazer isso, estabeleceu as bases do (seu) pragmatismo. Notemos, entrementes, que quando Peirce critica explicitamente o "espírito do cartesianismo", mais do que tratar do Descartes histórico, está, na verdade, referindo-se a um conjunto preciso de problemas: a intuição, a autoconsciência intuitiva-introspectiva e a certeza epistemológica subjetiva.

Grosso modo, o ponto de apoio dessa subjetividade a que se dirige a recusa peirciana é uma concepção voltada para uma consciência reflexiva que procura compreender primeiramente a sua própria existência interior e privada como base e pressuposto de toda compreensão possível. A idéia de sujeito da consciência, nesses termos, vem identificada à de um "eu" que representa a si mesmo sem as sombras do erro e da ilusão - posto que o "eu" diante de si, diferentemente de quando está diante de um objeto, não pode, sob qualquer hipótese, estar enganado. A consciência da consciência é uma "percepção interna" e uma intencionalidade que se dobra sobre si mesma, tornando-se objeto de ou para a consciência: é a consciência da consciência que forma e constitui a sustentação sólida da consciência e do conhecimento do ser, das coisas externas e das outras mentes².

A crítica negativa de Peirce a essa concepção de subjetividade (e daí, de imediatidade, de dado puro da experiência, de percepção interna, de introspecção, de intuição) anuncia as bases do pragmatismo vindouro. Jacques Poulain ${ }^{3}$ fala de um "héritage anticartésien" a partir de Peirce, que se estende a Davidson, Putnam e Rorty, conquanto ao pragmatismo esteja associada uma refutação do fundacionismo e do

${ }^{2}$ Cf. BICCA, 1997.

3 POULAIN, 1992, p. 23 seq. 
"mito do subjetivo". É da formação dos primeiros termos do testamento "anticartesiano" em Peirce que tratarei a seguir ${ }^{4}$.

Para os limites deste artigo, concentrar-me-ei em alguns temas e textos do jovem Peirce5: a) a rejeição da intuição; b) a crítica ao "espírito do cartesianismo"; e c) o problema da "terapia das idéias", assim como aparecem em "Questions Concerning Certain Faculties Claimed for Man" e "Some Consequences of Four Incapacities" de 1868, "The Fixation of Belief" de 1877 e "How to Make Our Ideas Clear" de 18786. Esses temas e textos se integram em torno de um núcleo comum: uma compreensão do espírito (mind) e do conhecimento assentada em critérios publicistas, semióticos, intersubjetivos e falibilistas ("héritage anticartésien"), e a idéia de um processo cognoscitivo sem fim definido e sem início absoluto no movimento de um pensamento que ultrapassa os indivíduos singulares.

\section{Intuição e verdade: diante das coisas, diante de si}

Para Peirce, o "espírito do cartesianismo" é a filosofia que ensina "que a comprovação final da certeza encontra-se na consciência individual"7. Tal ensinamento estabelece que a fonte e o critério da certeza

\footnotetext{
${ }^{4}$ Não me ocuparei, neste artigo, com uma avaliação das teses metafísicas e epistemológicas em Descartes, mas apenas com a recepção e interpretação que faz delas Peirce; noutro lugar explorei mais detidamente aspectos da obra de Descartes (SILVA FILHO, 1999). No artigo "Pragmatismo e ceticismo", ainda inédito, discuto o modo como W. Sellars, D. Davidson, H. Putnam e R. Rorty reelaboram a "crítica negativa" ao fundacionalismo epistemológico. Para uma apresentação crítica da relação de Peirce com a história do pragmatismo, ver MURPHY (1993), COMETTI (1994) e MOUNCE (1997).

${ }^{5}$ Existem muitas dificuldades em se apresentar uma visão de conjunto da filosofia de Peirce. Tendo publicado pouco em vida, ele deixou um espólio literário que, passados oitenta anos da sua morte, ainda não foi estabelecido e teve uma edição definitiva: são alguns milhares de manuscritos inéditos e esboços de obras que nunca vieram a lume. Atualmente, o Peirce Edition Project, coordenado pelos Prof. Nathan Houser e Christian Kloesel, entre outros, com sede na Indiana University (Bloomington, EUA), publica os Writings of Charles S. Peirce: A Chronological Edition, uma edição integral dos escritos de Peirce. Por isso, é imprudente falar em coisas do tipo "o pensamento de Peirce" ou "a filosofia de Peirce". Podemos encontrar introduções competentes aos vários aspectos e fases da obra de Peirce em WIENER (1952), GALLIE (1970), THIBAUD (1975), ALMEDER (1980), FREEMAN (1983), CHENU (1984), DELLEDALE (1979 e 1990), HAUSMAN (1993), CHAUVIRÉ (1995) e MERRELL (1998), com destaque para HOOKWAY (1992), MURPHEY (1993) e MERRELL (1995).

${ }^{6}$ Para fazer remissão aos textos de Peirce usarei a abreviatura $\mathrm{CP}$ na referência aos Collected Papers of Charles S. Peirce seguida do número do volume e do parágrafo citado.

7 PEIRCE, CP 5.264.
} 
gnoseológica devem estar baseados numa atividade fundamental e primeira do espírito: uma verdade indubitável e evidente em si; uma relação representacional-correspondentista entre dois termos, absolutamente simples, entre uma mente cognoscente e 0 fato, objeto ou verdade; uma metafísica para a qual qualquer fato ou objeto revelado por essa faculdade é como é e não depende de nenhum outro pensamento; uma epistemologia que parte, como base e garantia, de crenças de partida (absolutamente certas) que não necessitam ser justificadas porque se referem aos dados imediatos do espírito.

Descartes esteve interessado, nas suas $M$ editationes de prima philosophia ${ }^{8}$ e nos Principia Philosophiae ${ }^{9}$, entre outras coisas, com a seguinte interrogação: na busca de um princípio filosófico de clareza e distinção do entendimento, é possível julgar com validade se uma idéia corresponde a alguma coisa de real? Ou seja, como a realidade externa a mim responde às exigências internas do entendimento e da razão? ${ }^{10} M$ as Descartes não se pergunta apenas se as coisas, como objetos externos existentes, correspondem às verdades que o eu toma como essências, mas, outrossim, se as idéias que o eu acredita claras e distintas podem ser garantidas como verdadeiramente essências. Ou seja, se isso que 0 eu afirma - em nome da sua razão - expressa uma razão universal objetiva, e não apenas um delírio pessoal ${ }^{11}$.

Nesses termos, o tema da apreensão imediata (e certa, sem margem para o engano e erro) do objeto pelo espírito como princípio e fundamento do conhecimento assume sua força: a intuição, em toda a tradição filosófica, quer significar essa relação direta e integral, ou seja, uma relação entre o sujeito cognoscente e seu objeto que prescinde de quaisquer mediações; uma relação que exige a presença efetiva do objeto do espírito (Descartes fala, antes de mais nada, de uma intuição evidente que leva, ao lado da dedução necessária, ao conhecimento certo). Essa intuição do espírito deve alcançar não apenas as coisas, mas também as operações necessárias do próprio espírito e tudo aquilo que 0 intelecto experimenta com exatidão na vida corpórea, na ciência, na imaginação e no sonho.

Descartes pergunta se é possível o eu se enganar nisto que chamamos de intuição mesma das idéias. Se isto for possível, mesmo que hipoteticamente, e se o eu vier a descobrir que suas intuições podem, por algum motivo, estar enganadas, como se poderia vir a estar seguro de que isto que se conhece por intuição é verdadeiro? Isto é grave porque a mais firme de todas as certezas deveria ser oferecida exatamente

\footnotetext{
${ }^{8}$ DESCARTES, 1988.

9 IDEM, 1950.

${ }^{10}$ GUEROULT, 1953, p. 31.

11 IBIDEM, p. 32.
} 
pela intuição. Se a intuição falha ou se engana, onde estará a certeza, qualquer que seja?

Quando procura compreender o legado cartesiano, Peirce, no entanto, evita definir a intuição nos termos corriqueiros como apreensão imediata ou como forma pura de uma sensibilidade mística ou inexplicável. A intuição é, outrossim, uma compreensão do presente enquanto presente, ausência de determinação e de causa ou, segundo seu vocabulário lógico, "premissa que não é ela mesma uma conclusão", "conhecimento não determinado por um conhecimento anterior": “... o termo intuição será tomado como significando uma cognição não determinada por uma cognição prévia do mesmo objeto, e que, portanto, está determinada por algo exterior à consciência"12.

Falar de intuição, nessa circunscrição, é falar de um conhecimento "oposto do conhecimento discursivo" ${ }^{13}$ e da supressão do "significado" e, consequentemente, da "verdade", pois o "dado intuitivo", ao escapar à ordem discursiva, deve ser anterior lógica e cronologicamente a qualquer conceito, série, regra e enunciado. Assim, uma intuição só poderia ser concebida como uma premissa absolutamente primeira que, por sua vez, não fora determinada por nenhuma outra proposição senão pelo seu objeto transcendente, ou seja, uma proposição cujo objeto é, por definição, exterior, imediato e irrefletido. Exterior, entendamos bem, tanto no sentido de objeto exterior à mente (como no realismo fisicalista) quanto como um objeto ideal transcendental (como no realismo platônico), mas que comparece especularmente ao espírito. Um tal conhecimento imediato e presente implica na existência de uma mente como receptáculo vazio de juízos e inclinações e na existência de algo exterior no mundo físico ou no mundo das idéias.

Mas é aqui onde está a novidade: não é exatamente a noção de intuição que deve ser questionada, mas a prova da intuição, ou seja, o que necessita ser esclarecido é se podemos saber se uma cognição é intuitiva (nascido da experiência pura e imediata) ou não, se uma intuição pode ser, ela mesma, conhecida imediatamente, e, então, intuitivamente. Por isso, em "Questions Concerning Certain Faculties Claimed for Man" Peirce pergunta se, "pela simples contemplação de um conhecimento, independentemente de qualquer conhecimento anterior e sem raciocinar a partir de signos, estamos capacitados a julgar com correção se esse conhecimento foi determinado por um conhecimento prévio e se reporta imediatamente a seu objeto [grifos meus]" ${ }^{14}$. 0 problema é: uma intuição é conhecida intuitivamente? (Uma outra pergunta é se "temos

\footnotetext{
12 PEIRCE, CP 5.213.

${ }^{13}$ Cf. CHAUVIRÉ, 1979.

${ }^{14}$ PEIRCE, CP 5.213.
} 
um poder intuitivo de distinguir entre os elementos subjetivos de diferentes gêneros de conhecimentos"15). Há uma diferença entre "ter uma intuição" e "saber intuitivamente que isto é uma intuição"16. No fundo, não haveria dificuldades em se aceitar o sentido da idéia de um conhecimento que, entendido como algo que está presente imediatamente à mente, poderia ser reconhecido como "uma intuição de si mesmo". No entanto, o que incomodará a Peirce é saber se estes dois termos (ter intuições; saber intuitivamente que isto é intuição), distinguíveis conceitualmente, estão conectados ao ponto que, em algum momento, possamos ter a capacidade de estabelecer uma real diferença entre, de um lado, uma intuição conhecida intuitivamente e, do outro, um conhecimento não-intuitivo determinado por um outro conhecimento (uma inferência).
"Não há evidências de que temos esta faculdade, exceto que parecemos sentir que a temos. Mas o peso desse testemunho depende inteiramente do fato de se supor que nos é dado o poder de distinguir neste sentimento, se o sentimento é o resultado de educação, velhas associações, etc. ou se é uma intuição cognitiva; ou, em outras palavras, depende de se pressupor a própria matéria sobre a qual versa o testemunho. É este sentimento infalível? E é o juízo que a ele diz respeito infalivel, e assim por diante, ad infinitum?[grifos do autor]" ${ }^{17}$.

Seria possível estabelecer um raciocínio que parta de um princípio que não tenha sido formado na nossa vida real e concreta pela educação e pelos hábitos e, sendo assim, fosse infalível? Como saber se esta certeza nasceu intuitivamente ("reporta imediatamente ao seu objeto") ou foi aprendida na rede pública das regras lógicas compartilhadas pela comunidade ("conhecimento prévio")? Para responder positivamente à primeira pergunta deveríamos estabelecer uma descrição da vida psíquica a partir de uma compreensão direta de fatos psíquicos ou espirituais e supor um caráter privilegiado e primeiro da consciência de si. Uma psicologia introspectiva seria o fundamento epistemológico e a consciência intuitiva de si (a capacidade de distinguir intuitivamente entre as diferentes atividades do espírito como perceber, imaginar e sonhar) seria a fonte primeira das evidências e da verdade. Assim, consciência de si viria separada da consciência em geral, precedendoIhe lógica e ontologicamente; a "autoconsciência" - a consciência intuitiva da consciência - seria a primeira, no tempo e na razão, consciência. Mas para que ela cumpra sua função, deveria estar alheia a qualquer conceito e crença e não poderia sofrer a influência de qualquer outra cognição:

"A Autoconsciência [self-consciousness] ou autoconcepção como entendo, deve ser distinguida tanto da consciência em termos gerais, quanto do sentido interno

\footnotetext{
15 IBIDEM, 5.238.

16 IBIDEM, 5.214.

17 IBIDEM.
} 
e da pura apercepção. Toda cognição é uma consciência do objeto tal como é ele representado; por autoconsciência entende se um conhecimento de nós mesmos. Não mera sensação das condições subjetivas da consciência [...]. A pura apercepção é a auto-asserção do ego; a autoconsciência, tal como aqui se entende, éa recognição de meu eu privado. Sei que eu (não apenas o eu) existo. A questão é: como sei disso: por uma faculdade intuitiva especial ou esse conhecimento é determinado por cognições prévias?[grifos do autor]"18

0 embaraçante é que a consciência que temos de nós mesmos como seres particulares não é de natureza intuitiva. 0 self-consciousness é um discurso que integra dados passados (o que fomos no passado pelo testemunho da memória, dos documentos, fotografias e do relato dos outros) e as antecipações ("Irei almoçar com Maria amanhã") e é, no fundo, uma construção discursiva proveniente de diversos dados e fontes. Recorrendo a um expediente comum a Wittgenstein - uma pseudopsicologia infantil - Peirce diz que não se observa nas crianças traços de uma tal consciência intuitiva de si como requisito para conhecer as coisas. A criança manifesta capacidades de pensar bem antes de ter consciência de seu eu. Essa aquisição de capacidades é devida essencialmente à descoberta da relação central de seu corpo e, sobretudo, à experiência de ignorância e de erro no câmbio com o mundo e com os outros homens e mulheres. É pela mediação da linguagem que Ihe ensinam que a criança toma consciência de que as palavras dos outros classificam e categorizam as coisas; nesse mesmo movimento, na compreensão da sua ignorância e do seu erro, quando se dá conta que as advertências dos adultos são confirmadas na experiência e suas antecipações expontâneas infirmadas é que começa a se formar sua auto-imagem. 0 testemunho e a linguagem do outro do outro dá "o primeiro esboço da autoconsciência" ${ }^{19}$. A criança tem a experiência do erro, e o erro não pode ser explicado senão supondo um eu que seja o sujeito, e o lugar do erro e do acerto, do real e do irreal, da verdade e da falsidade, é algo que se aplica não apenas a ele, mas a todos: "A ignorância e o erro são tudo aquilo que distingue nossos eus privados do Eu absoluto da apercepção pura"20. Ou, o que é mais grave, a certeza infalível, imediata, aportada na autoridade da primeira pessoa do singular, ao interditar a possibilidade do erro, proíbe 0 acerto e a verdade: "Supondo-se que um homem realmente pudesse encerrar-se numa fé desse tipo, ele seria, por certo, impermeável à verdade" ${ }^{21}$.

A consciência que temos de nós mesmos tem inexoravelmente a característica inferencial (mesmo que as inferências que adotemos nos induzam a considerar tal consciência como imediata). Como recorrer à

\footnotetext{
18 IBIDEM, 5.225

19 IBIDEM, 5.233.

20 IBIDEM, 5.235 .

${ }^{21}$ IBIDEM, 5.214.
} 
"autoconsciência intuitiva" como o "primeiro conhecimento" se nossa consciência é o resultado de conjecturas e hipóteses adquiridas pela educação e pela convivência com os outros? Seria confortável se tivéssemos a capacidade de separar intuitivamente o que acreditamos e 0 que concebemos, o que aprendemos e o que irrompe à nossa experiência:

"E se não dispuséssemos de nenhum poder intuitivo para distinguir entre aquilo que acreditamos e aquilo que meramente concebemos, jamais poderíamos, ao que parece, distingui-los; dado que se o fizéssemos através do raciocínio, colocarse ia a questão de saber se o próprio argumento foi acreditado ou concebido, e isto deve ser respondido antes que a conclusão possa ter alguma força [grifos meus]. E assim haveria um regressus ad infinitum"22.

Como se encerra esse círculo vicioso? Ora, não se pode negar que temos um conhecimento da nossa vida espiritual, mas o conhecimento do mundo interno (da imaginação, das emoções... ) passa, inexoravelmente, pelo conhecimento daquilo que foi externalizado e significado, ou seja, daquilo que representa algo para seu intérprete os fatos internos só podem ser apreendidos através da concatenação de fatos externos.

\begin{abstract}
"Se nos baseamos nos fatos externos, os únicos casos de pensamento que encontramos são de pensamento em signos. Não há, de modo claro, qualquer outro pensamento que possa ser evidenciado pelos fatos externos. Mas já vimos que é só através dos fatos externos é que o pensamento pode ser em geral conhecido. Desta forma, o único pensamento possivelmente conhecível é o pensamento em signos. Mas um pensamento que não se pode conhecer não existe. Cada pensamento deve necessariamente ser um pensamento em signos [grifos meus]"23.
\end{abstract}

Signo aqui é qualquer coisa que, sob certos aspectos e qualidades, representa algo para alguém, criando na mente ${ }^{24}$ do intérprete uma representação da representação, ou melhor, um novo signo equivalente àquele primeiro signo ou mais desenvolvido que el ${ }^{25}$. É um grave erro imaginar que, para Peirce, o pensamento é uma realidade espiritual e auto-suficiente (que, ao seu bel-prazer, serve-se voluntária e arbitrariamente da linguagem para se manifestar ou comunicar) e o signo, uma representação mental ${ }^{26}$. Se pensarmos no caso de um signo

\footnotetext{
22 IBIDEM, 5.239.

23 IBIDEM, 5.251.

24 Peirce usa a expressão almost-mind (CP 4.536).

${ }^{25}$ Não posso discutir, nos limites deste artigo, o conceito e a doutrina dos signos (e a doutrina das categorias) em Peirce. Para uma discussão sobre o conceito de signo em Peirce, ver ECO (1973 e 1984), PEIRCE (1978), DELLEDALE (1979) e MERRELL (1997).

${ }^{26}$ Como, por exemplo, vem expresso na tradição do empirismo moderno, de Locke a Berkeley, Hume e Mill. Sobre a concepção mentalista do signo e do significado, ver SILVA FILHO, 1999.
} 
convencional, como é o caso das palavras, pode parecer que ele exige um pensamento incoativo anterior para fixar o sentido. Peirce rejeita explicitamente que o pensamento seja anterior em relação aos signos. Todo pensamento é, em si, de natureza simbólica, consistindo na manipulação de signos. Para ele, realmente, o signo necessita de algo anterior que fixe o seu significado, mas este anterior é também um signo. O signo convencional interpreta signos anteriores e é interpretado por outros signos que suscita: não há signo que não exija uma certa forma de interpretação e não remeta, ele mesmo, a um signo. Por isso, o signo não é uma representação no sentido da concepção mentalista do empirismo, mas uma relação que envolve a linguagem, o mundo, o corpo, a regra, o geral ${ }^{27}$. A grande distância entre Peirce a as teorias lingüísticas do signo ${ }^{28}$ se deve, principalmente, ao fato de que nosso autor está ocupado com uma teoria do conhecimento e uma teoria do espírito (philosophy of mind) que resolva a dicotomia mente-mundo, diluindo o conceito correspondentista de representação e, ao mesmo tempo, preserve o sentido positivo do conhecimento do real. Da lição nominalista que extraiu de Ockham e Scot, Peirce sabe que o pensamento se dirige ao particular e singular na experiência real dos fatos exteriores, mas faz isso recorrendo a relações, conexões, séries, signos e inferências. 0 pensamento só pode ser um pensamento simbólico porque não pode ser senão um pensamento de termos gerais e leis. Como em Aristóteles, do puro particular e singular não se conclui nada, não se infere nada, não se conhece.

Há em Peirce uma concepção falibilista do conhecimento ${ }^{29}$ : ele reconhece francamente que em todas as nossas pretensões de conhecimento subsiste um elemento de hipótese não verificada e, portanto, que a ordem que orienta a formação do nosso discurso sobre as coisas depende da ordem de convicções, noções e conceitos dos quais se parte ${ }^{30}$. É por

\footnotetext{
${ }^{27}$ Independente do fato de que não há uma exposição completa e acabada de uma doutrina dos signos em Peirce, o que compõe genericamente o signo são os seguintes aspectos: a) a função do signo (chamado por Peirce de representamen) é a de requerer um objeto (object) de significação; b) o signo-representamen refere-se a este object; c) o object é capaz de determinar um outro signo que o interpreta (ou interpretante): "Um signo ou representamen é algo que significa algo para alguém segundo certos aspectos e capacidades. Dirige-se a alguém, isto é, cria na mente dessa pessoa um signo equivalente ou talvez um signo mais desenvolvido. O signo assim criado denomino interpretante do primeiro signo. O signo representa alguma coisa, seu objeto. Representa esse objeto não em todos os seus aspectos, mas com referência a um tipo de idéia que eu, por vezes denominei base [ground] do representamen [grifos do autor]." (PEIRCE, CP 2.228)

${ }^{28}$ Sobre a crítica ao paradigma lingüístico em semiótica, ver ECO (1973 E 1984), DELEDALLE (1979), MERRELL (1995).

${ }^{29}$ Sobre a concepção falibilista do conhecimento em Peirce e sua relação com a filosofia de Popper, ver CHAUVIRÉ (1981).

30 GALLIE, 1970, p. 66.
} 
isso que cada caso de consciência aparentemente direta e intuitiva (por exemplo, a consciência dos mais elementares dados presentes no espírito) tem a natureza de uma hipótese porque cada pretensão de conhecimento comporta uma suposição que se aplicará relativamente a um objeto ou a uma série de objetos a partir de um certo método de classificar, enunciar e sistematizar ${ }^{31}$.

No "puro presente imediato" não há pensamento e, do mesmo modo, na intuição não há operações da consciência que se assemelhem ao uso normal do conceito de pensamento. Por "pensamento" ou "conhecimento", Peirce entende uma compreensão, uma intellection, um trabaIho de estabelecer relações e cadeias que demanda tempo, e não uma simples presença. Não pode haver um conhecimento propriamente dito do presente imediato, nem do absolutamente imediato:

"Da proposição de que todo pensamento é um signo, segue se que todo pensamento deve endereçar-se a algum outro pensamento, deve determinar algum outro pensamento, uma vez que essa é a essência do signo. Assim, esta não passa de uma outra forma do axioma familiar segundo o qual na intuição, i.e., no presente imediato, não há pensamento ou que tudo aquilo sobre o que se reflete tem um passado. [...] $O$ fato de que a partir de um pensamento deve ter havido um outro pensamento tem um análogo no fato de que a partir de um momento passado qualquer deve ter havido uma série infinita de momentos. Portanto, dizer que 0 pensamento não pode acontecer num instante, mas que requer um tempo, não é senão outra maneira de dizer que todo pensamento deve ser interpretado em outro, ou que todo pensamento está em signos"132.

A observância a "fatos externos", longe do realismo metafísico, remete àquilo que podemos chamar provisoriamente de externalismo semiótico ou realismo pragmático ${ }^{33}$. Ora, aqui há um imperativo hermenêutico que afirma que todo pensamento determina um outro pensamento que 0 interpreta, e, reciprocamente, todo pensamento supõe um outro do

\footnotetext{
31 IBIDEM, p. 63.

32 PEIRCE, CP 5.253.

33 Procurarei desenvolver o tema do realismo pragmático na pesquisa "Principia realitas: linguagem, mente e mundo segundo a compensação dogmática do pragmatismo" sob os auspícios da PPPG/UFBA e do PRODOC (CADCT/UFBA/ FAPEX). Considero decisivo para os argumentos do pragmatismo que em Putnam, Davidson e Peirce há a vindicação de um realismo pragmático. A realidade é tal como é concebida, relativa ao aparato conceitual que utilizamos para falar e representar o mundo tal qual. No entanto, mesmo que a realidade seja relativa à linguagem e aos esquemas conceituais que dispomos, isto não significa que não podemos deter critérios que apontem para a diferença entre fatos reais e não reais, e entre enunciados verdadeiros e falsos acerca dos fatos. Para Putnam, o realismo pragmatismo recebe o nome de "realismo interno", pelo que se deve entender "... a insistência em que o realismo não é incompatível com a relatividade conceitual. Se pode ser ao mesmo tempo um realista e um relativista conceitual. O realismo (com um ' $r$ ' minúsculo) (...) é a perspectiva que toma nosso esquema do sentido comum familiar; tanto como nossos esquemas científicos, artísticos e outros, no sentido literal, sem apoiar-se na noção de 'coisa em si mesma'."
} 
qual ele é uma interpretação. Esta é a base da Semiótica e do realismo peirciano, a saber, que todo pensamento por signo seja "determinado" por um outro pensamento e, a seu turno, "determinante" de um outro.

Peirce ainda pergunta se "um signo pode ter algum significado se, por definição, é um signo de alguma coisa absolutamente incognoscível" 34 . Faz isso para estabelecer a impossibilidade teórica de qualquer concepção do incognoscível e do objeto epistemologicamente não-sígnico, ou seja, daquilo que não é determinado, de algum modo, por algum conhecimento anterior e que escapa a todas as nossas formas de classificar, seriar e pensar.

“... todas nossas concepções são obtidas por abstrações e combinações de cognições que ocorrem inicialmente nos juízos da experiência. Por conseguinte, não pode haver uma concepção do absolutamente incognoscível, uma vez que nada disso ocorre na experiência. Mas o significado de um termo é a concepção que ele veicula. Por conseguinte, um termo não pode ter um significado desse tipo"135.

0 termo "incognoscível" advém de uma contradição, pois qualquer idéia que defina algo além do conhecimento possível (baseado no estágio atual do conhecimento) é o resultado de um abuso da linguagem. Todo pensável é concebível, e o que é concebível na realidade deve ser teoricamente cognoscível e significável: se algo é da natureza dos signos e do significado é, como tal, um conceito do cognoscível. A intuição, sim, operaria com o absolutamente incognoscível, porque lidaria com aquilo que não participa da linguagem e do conhecimento prévio. Mas 0 incognoscível (se existe algo como isso) simplesmente não tem qualquer relação com o pensamento, muito menos com a formação de uma base sólida para a construção de uma imagem do real e da verdade.

Porque, de um modo geral, nós não temos o poder de distinguir intuitivamente um modo de conhecimento intuitivo do não-intuitivo, não podemos, do mesmo modo, distinguir, neste conhecimento que está presente à nossa consciência, aquilo que é dado e aquilo que é construído, senão pelo entendimento, com a ajuda de materiais extraídos da inferência. Cada acontecimento conhecido - por exemplo, a irrupção de uma nova experiência - não é um fato instantâneo, mas um processo contínuo que é interpretação ininterrupta de pensamentos por outros pensamentos e fusão de impressões nas representações que the dão unidade e sentido ${ }^{36}$. Indicar a cognição pela qual um conhecimento ou signo foi determinado é explicar e dar significado às determinações daquela cognição ${ }^{37}$ : este é 0 único modo de explicar 0 conhecimento de si, das coisas e da mente dos outros.

\footnotetext{
34 PEIRCE, CP 5.254.

35 IBIDEM, 5.255.

${ }^{36}$ CHENU, 1984, p. 112.

${ }^{37}$ PEIRCE, CP 5.260 .
} 
A idéia de que não há pensamento sem signo, e que signo é interpretação e inferência, subverte o valor fundante da intuição pura e da consciência intuitiva de si e abala o sentido forte de subjetividade. Voltaremos a este assunto mais adiante.

\section{A dúvida sincera e a dúvida insincera}

Há ainda um problema epistemológico e metodológico na filosofia do espírito do cartesianismo: como a razão poderá seguir na trilha correta e esclarecida? Para resolver esse problema, o cartesianismo, escreve Peirce, ensina "que a filosofia deve começar com a dúvida universal" 38 .

"Quando Descartes se propôs reconstruir a filosofia, seu primeiro passo foi no sentido de (teoricamente) possibilitar o ceticismo e afastar o hábito de os escolásticos verem na autoridade a fonte última da verdade. Feito isso, buscou ele uma fonte mais natural de princípios verdadeiros e acreditou encontrá-la na mente humana; e, dessa maneira, passou, pelo caminho mais imediato, do método da autoridade para o do apriorismo [...]. Cabia à própria consciência oferecer-nos as verdades fundamentais e decidir do que fosse agradável à razão. Entretanto, como, evidentemente, nem todas as idéias são verdadeiras, Descartes foi levado a assinalar, como primeira condição de verdade, o serem claras as idéias. Distinção entre uma idéia aparentemente clara e realmente clara nunca Ihe ocorreu. Confiando na introspecção como confiava, mesmo para o conhecimento das coisas externas, por que iria questionar seu testemunho com respeito ao conteúdo de nossos próprios espíritos? M as suponho eu, ao ver homens que pareciam claros e positivos sustentarem opiniões opostas acerca de princípios fundamentais, Descartes foi conduzido a afirmar não bastar a clareza das idéias, que deveriam ser, a par disso, distintas, isto é, não haver a propósito delas nada de obscuro. 0 que Descartes provavelmente quis dizer (pois que não se explicou com precisão), foi que as idéias devem resistir ao teste do exame dialético, devem não apenas parecer inicialmente claras, mas ser impossível um debate fazer emergirem pontos obscuros com elas relacionados [grifos meus]." 39

Descartes, como sabemos, procede numa auto-interrogação, sem, no entanto, estar disposto a abrir mão da certeza total. Ele pretende examinar toda a esfera da certeza e não admite apenas pensar que está certo: estar certo pode ser a ilusão de estar certo, uma crença cega numa certeza que ele mesmo não pode controlar. Se se ignora os fundamentos da certeza, como se poderia distinguir a certeza verdadeira da certeza ilusória (como no sonho e no delírio)? A saída da incerteza, como comumente é relacionada ao cartesianismo, reúne dois ingredientes: a)

\footnotetext{
38 IBIDEM, CP 5.264.

39 IBIDEM, 5.391.
} 
a necessidade de uma dúvida inicial e hiperbólica e; b) a necessidade de tratar provisoriamente como falsas as coisas duvidosas.

Com a dúvida hiperbólica dá-se um passo decisivo na rejeição de tudo aquilo que, imediatamente, não é seguro, claro e distinto, a saber, 0 princípio segundo o qual o conhecimento vem dos sentidos.

“... tudo aquilo que até ao presente admiti como maximamente verdadeiro foi dos sentidos ou por meio dos sentidos que o recebi. Porém descobri que eles por vezes nos enganam, e é de prudência nunca confiar totalmente naqueles que, mesmo uma só vez, nos enganaram." ${ }^{\prime 40}$

Mas esta é apenas uma etapa inicial e natural do entendimento. Será necessário, mais adiante, aplicar a dúvida aos próprios objetos do espírito.

Descartes havia dividido as idéias em duas categorias: aquelas que são compostas e aquelas que são simples (e que tanto podem ser intelectuais ou espirituais, como podem ser sensíveis). Mais do que se dirigir às idéias sensíveis, são as idéias compostas, de antemão, que estão postas sob suspeita; elas são factícias, ou seja, são um conglomerado artificial, não-natural, secundário e derivado de idéias simples, às vezes indevidamente agrupadas (como, por exemplo, a idéia de "cavalo alado"). As idéias que são indecomponíveis ou simples (sejam intelectuais ou sensíveis), são necessariamente indubitáveis, porque não podem ser factícias: elas são noções primeiras e dados imediatos que se revelarão, mais tarde, pelo exame do entendimento, como idéias inatas.

A característica indubitável de uma sensação como idéia simples não compromete a conclusão relativa ao caráter enganoso do conhecimento sensível. Descartes permanecerá fiel à idéia de que tal conhecimento não se constitui senão pela combinação factícia de sensações ${ }^{41}$. No entanto, quando ataca a composição e a facticiadade de uma idéia, está, outrossim, examinando a natureza das percepções, porque (já Descartes sabia, mas é Edmund Husserl que irá levar às últimas conseqüências) o caráter da percepção é ser uma presença imperecedoura para 0 percepiente. Frente a uma percepção, estamos diante não de algo verdadeiro ou falso, real ou irreal, mas do percebido, como se dá, por exemplo, na alucinação e no sonho. Um dos argumentos mais ricos do cartesianismo é o seguinte:

"Com efeito, quantas vezes me acontece que, durante o repouso noturno, me deixo persuadir de coisas tão habituais como estou aqui, com o roupão vestido, sentado à lareira, quando, todavia, estou estendido na cama e despido. Mas agora observo

40 DESCARTES, 1988, p. 107.

${ }^{41}$ IBIDEM, p. 35. 
este papel seguramente com os ol hos abertos, esta cabeça que movo não está dormindo, voluntária e conscientemente estendo esta mão e sinto-a: o que acontece quando se dorme não parece tão distinto. Como se não me recordasse de já ter sido enganado em sonho por pensamentos semelhantes! Por isso, se reflito mais atentamente, vejo com clareza que vigília e sono nunca se podem distinguir por sinais seguros, o que me espanta - e é tal este meu espanto que quase me confirma na opinião de que durmo." [grifo meu ]2

Para Descartes, vigília e sonho não se distinguem, porque a primeira é uma percepção verdadeira de coisas reais, e o segundo, uma percepção falsa de irreais. Com a diluição desta modalidade de critérios de distinção se dá uma modificação, de largas conseqüências, do conceito de "verdade": não diz respeito à correspondência da realidade exterior às nossas percepções reais e verdadeiras, mas, outrossim, à natureza da inteligência que é capaz de examinar aquilo que é tomado por verdade e realidade. Essa inteligência reúne tudo aquilo que é claro e distinto aos seus olhos (yeux de l'intelligence) como consciência clara. "Verdade" e "realidade" é tudo aquilo que, submetido às regras do entendimento (regulae ad directionem ingenii), mostra-se indubitavelmente claro.

Por esse motivo, na vigília, por si só, não estamos mais seguros do que no sonho, mesmo porque não temos condições de estabelecer, de modo absolutamente seguro, se estamos acordados ou dormindo.

Há uma impossibilidade de sair do círculo da presença da percepção, pois perceber objetos, no seu sentido estrito, é estar na presença atual e irrevogável do objeto percebido. Jean-Paul Sartre, no L'imaginaire, indaga-se: se é verdadeiro que o sonho se realiza como um mundo real e percebido, podemos pensar que o modo como elaboramos imagens em geral obedece um princípio comum ao sonho e à vigília. 0 fato comum é que "quando eu percebo, não estou seguro de que os objetos da minha percepção existem, mas eu estou seguro que os percebo" $^{43}$. Por isso, talvez não fosse possível apontar as fronteiras do real e da imaginação; isso, no entanto, não proíbe o sentido de verdade em Descartes. Porque a verdade não se encontra na percepção nem em quaisquer critérios externos. No trabalho analítico do entendimento, decompondo as imagens complexas e factícias nos elementos simples e gerais que os torna possíveis, Descartes se desloca do fato à regra, isto é, ele parte das representações dadas para chegar às condições necessárias, universais, de toda representação, tanto imaginária quanto real. Passa-se da esfera do existente à esfera do possível, envolvendo toda existência concebível. A verdade é a verdade das idéias na sua realidade própria, sem que nos perguntemos se existem na natureza ou não; é verdadeiro que o quadrado tem quatro lados, mesmo que ele não

42 DESCARTES, 1988, p. 108.

${ }^{43}$ SARTRE, 1986, p. 310. 
exista na natureza; independente da sua existência ou não, ele não deixará de ter quatro lados; do mesmo modo, $2+3$ é necessária e universalmente 5, quer a natureza assim o mostre ou não. "... quer eu esteja acordado quer durma, dois e três somados são sempre cinco e o quadrado nunca tem mais do que quatro lados; e parece impossível que verdades tão evidentes possam incorrer na suspeita de falsida$\mathrm{de}^{\prime \prime} 4$.

É porque tratam de coisas tão fortemente simples e abstratas que a aritmética, a geometria e outras ciências da mesma natureza contêm algo de certo e indubitável... distintamente da física, da astronomia, da medicina e de todas as ciências que, dependentes da consideração de coisas compostas, são duvidosas e incertas ${ }^{45}$. 0 princípio da decomposição do composto no simples não permite que se vá além do elemento indecomponível e logicamente primeiro: a impossibilidade de duvidar advém da impossibilidade de ir além da decomposição e da análise.

É importante, no entanto, termos claro, como solicita Gueroult ${ }^{46}$, que para Descartes o simples ato natural de trazer em causa uma "dúvida de partida" não esgota inteiramente sua crítica do conhecimento. 0 ato de rejeitar voluntariamente como falsas algumas idéias é 0 mais forte dos testemunhos que confirmam a intervenção da liberdade do espírito, que não apenas suspende 0 julgamento, mas produz um julgamento negativo para melhor esclarecer as coisas. Há, aqui, uma passagem do plano da natureza do espírito individual ao plano da metafísica e da espiritualidade em geral; essa passagem transcende 0 individual e o coloca em questão, fazendo surgir, no processo da dúvida exaustiva, uma descontinuidade possibilitada pela intervenção do livre arbítrio. Se podemos nos elevar além da esfera do nosso entendimento finito, para atingir em bloco valores de noções que se apresentam como necessárias e certas, é porque dispomos de um poder superior, infinito, capaz de despender um esforço contra a natureza.

Por essa passagem da dúvida hiperbólica, fundada em razões naturais, à dúvida metafísica, o entendimento, mais do que justificar seus objetos, é solicitado a justificar a si. Isto que, para o entendimento, constitui a condição de possibilidade de toda representação, ou seja, de todo real concebível pelo eu, é condição de possibilidade de todo real em si? Aquilo que naturalmente estou inclinado a conceber é o mesmo que pode ser metafisicamente fundado (para mim e todos os espíritos)? ${ }^{47}$

\footnotetext{
44 DESCARTES, 1988, p. 110.

45 IBIDEM, p.109.

${ }^{46}$ GUEROULT, 1953, II.

47 IBIDEM, p. 38.
} 
Por isso, não só as coisas empíricas, mas todo o real deve estar sob suspeita. Donde deriva a tese mais radical do cartesianismo: combinando a noção de um Deus enganador, infinitamente poderoso, à ação do espírito no exercício da sua vontade infinita institui a ficção do "malin génie":

"Vou supor [...] não o Deus sumamente bom, fonte da verdade, mas um certo gênio maligno [malin génie], ao mesmo tempo extremamente poderoso e astuto, que pusesse toda a sua indústria em me enganar. Vou acreditar que o céu, o ar, a terra, as cores, as figuras, os sons e todas as coisas exteriores não são mais que ilusões de sonhos com que ele arma ciladas à minha credulidade. Vou considerarme a mim próprio como não tendo mãos, não tendo olhos, nem carne, nem sentidos, mas crendo falsamente possuir tudo isso. Obstinadamente, vou permanecer agarrado a este pensamento e, se por este meio não está em meu poder conhecer algo verdadeiro, pelo menos que me guarde com firmeza de dar assentimento ao falso, bem como ao que aquele enganador, por mais poderoso, por mais astuto, me possa impor." [grifo meu]

0 "malin génie" funda a necessidade de uma dúvida mais do que radical, uma dúvida total, como suspensão de todo julgamento sobre todas as coisas, incluindo o ator da frase "Eu". Ao fazer isso, anunciase a atitude categórica do sujeito além do eu empírico e pessoal, e inaugura-se o sujeito filosófico moderno; da dúvida radical e integral, podemos auspiciar uma única e suprema certeza: “... suponho que é falso tudo o que vejo. Creio que nunca existiu nada daquilo que a memória enganadora representa. Não tenho, absolutamente, sentidos; o corpo, a figura, a extensão, o movimento e o lugar são quimeras. Então, o que será verdadeiro? Provavelmente uma só coisa: que nada é certo" ${ }^{49}$.

Uma certeza absoluta: há uma coisa que a dúvida, mesmo metafísica, não poderá atingir; é a condição interna do ato de duvidar, condição que é imanente, a saber, a existência de meu pensamento. Assim, a dúvida metafísica, como a dúvida natural, é exorcizada pelo apelo às condições da dúvida. De um lado, se eu não posso duvidar naturalmente de noções matemáticas, é porque nelas falta a condição que torna possível a dúvida: a composição; a impossibilidade de duvidar se funda, aqui, sobre a natureza do objeto oferecido ao pensamento, e a certeza vem desse objeto. Por outro lado, se eu não posso duvidar metafisicamente do meu pensamento, é porque sua existência deve sempre ser afirmada na dúvida, como condição necessária desta operação mental; não se pode duvidar do pensamento que duvida ${ }^{50}$. A impossibilidade da dúvida se estrutura na gramática do próprio ato

\footnotetext{
${ }^{48}$ DESCARTES, 1988, p. 114.

49 IBIDEM, p. 118.

50 GUEROULT, 1953, p. 40.
} 
de duvidar e a presença necessária de sua condição sine qua non: a criatura pensante. A certeza vem unicamente do sujeito pensante.

“Não sou eu, então, pelo menos, alguma coisa? M as já neguei que tivesse quaisquer sentidos e qualquer corpo. Todavia, hesito: porque, o que se conclui daí? Estou ligado ao corpo e aos sentidos de modo que não possa existir sem el es? Mas persuadi-me que não havia absolutamente nada no mundo, nenhum céu, nenhuma terra, nenhum espírito, nenhum corpo. Não me persuadi também de que eu próprio não existia? Pelo contrário, eu existia com certeza se me persuadi de alguma coisa. Mas há um enganador, não sei qual, sumamente poderoso, sumamente astuto, que me engana sempre com a sua indústria. No entanto, não há dúvida de que também existo, se me engana; que me engane quanto possa, não conseguirá nunca que eu seja nada enquanto eu pensar que sou alguma coisa. De maneira que, depois de ter pesado e repesado muito bem tudo isto, deve por último concluir-se que esta proposição 'Eu sou, eu existo', sempre proferida por mim ou concebida pelo espírito, é necessariamente verdadeira" [grifos meus] ${ }^{51}$.

A dúvida cartesiana vai bem mais longe que a dúvida cética. Uma vez estabelecida uma ordem de razão para a dúvida, daí derivam as outras razões que sustentam a própria possibilidade da clareza, baseada na apercepção e na consciência de si. Se estivéssemos na dúvida sobre a própria consciência de si, mesmo assim, isso implicaria uma positividade. A função do cogito dá um tipo exemplar de enunciado garantido: o cogito é certo porque percebemos distintamente a união entre nosso pensamento (instanciado no eu) e a nossa existência. Ele é a testemunha de que o espírito pode atingir com plena distinção um objeto total.

"... só posso fazer um juízo sobre as coisas que conheço. Conheço que existo; pergunto o que é aquele eu de quem conheço isto. É certíssimo que este conhecimento do eu, tomado, por precisão, desta maneira, não depende daquelas coisas que ainda não conheço se existem, portanto, também não daquelas que imagino. E este verbo 'imaginar' adverte-me do meu erro: porque se eu imaginasse ser algo, na verdade representar-me-ia algo, uma vez que imaginar não é mais que contemplar a figura ou a imagem de uma coisa corpórea"52.

Tendo o pensamento expurgado todas as idéias e conceitos que vêm do mundo real e imaginado, pode, finalmente, estabelecer para si mesmo a convicção de um princípio a partir do qual qualquer outro enunciado se vê constrito. A certeza do eu, a consciência de si enquanto uma ordem de razões, enquanto uma evidência em si, é o único critério para o entendimento - do conhecimento do meu espírito derivam as garantias do conhecimento das coisas e de outros espíritos.

\footnotetext{
${ }^{51}$ DESCARTES, 1988, p. 119.

52 IBIDEM, p. 123-4.

53 IBIDEM, p. 124.
} 
"Mas que sou então? Uma coisa pensante [res cogitans]. O que quer dizer isto? Quer dizer: uma coisa que duvida, que compreende, que afirma, que nega, que quer, que não quer, que também imagina e que sente" ${ }^{\prime \prime 3}$.

A crítica peirciana se lança contra o sentido individualista e solipsista da pesquisa da verdade e da prática do conhecimento. Para ele, a verdade e a ciência não são afazeres de uma pessoa, mas afazeres coletivos de uma comunidade infinita de mulheres e homens integrada por uma crença e linguagem. Pelas razões que expomos acima, na primeira parte deste artigo, a compreensão que temos de nosso eu não pertence ao nosso domínio privado, mas outrossim, ao domínio do discurso público e semiótico (que localiza todos os conceitos de real, verdade, e conhecimento na vida de uma comunidade de inquérito).

Um comentador ${ }^{54}$ ressalta que, do ponto de vista do pragmatismo, a racionalidade humana consiste no hábito de apresentar consenciosamente o pensamento, de tal forma que sejam exibidas as razões (novas ou antigas, necessárias ou prováveis, suficientes ou contingentes) através de uma linguagem essencialmente pública. Segue disto que a "verdade" alcançada através da inferência é uma verdade pública, isto é, uma opinião verificada, aperfeiçoada e generalizada por meio da crítica de todas as mentes de uma presumível comunidade.

\section{Mas como a filosofia encontra suas primeiras razões?}

"Certos filósofos imaginaram que, para começo de uma investigação, bastaria colocar, por escrito ou oralmente, uma indagação, e chegaram a recomendar que indicássemos nossos estudos questionando tudo. Entretanto, o simples colocar uma proposição em forma interrogativa não estimula o espírito a lutar pela crença. Deve existir uma dúvida viva e real, sem o que toda discussão será vazia" ${ }^{\prime 5}$.

A dúvida é uma incitação ao agir, que tem alguma coisa de irritação nervosa que o organismo tende a eliminar pelos atos reflexos. A dúvida real e concreta é um estado desagradável e incômodo que procuramos nos livrar para atingirmos o estado de crença (que é um estado de tranqüilidade e satisfação que não desejamos evitar ou transformar na crença em algo diverso): “... apegamo-nos tenazmente não apenas a crer, mas a crer no que cremos" ${ }^{\prime 56}$. A crença é uma disposição que

\footnotetext{
54 GALLIE, 1970, p. 103.

55 PEIRCE, CP 5.376.

56 IBIDEM, 5.372.
} 
dirige a ação, e é uma condição natural da mente inquiritiva. Peirce diz: “... Nossas crenças orientam nossos desejos e dão contorno a nossas ações" 57 .

Nesta altura, fica evidente que o filósofo americano apoia-se em princípios semelhantes aos de Wittgenstei ${ }^{58}$ para apontar os contra-sensos da "dúvida universal" como base da certeza privada e da verdade daí derivadas. Para ele:

"Não podemos começar pela dúvida completa. Devemos começar com todos os preconceitos que realmente temos [...]. Estes preconceitos não devem ser afastados por uma máxima, pois são coisas a respeito das quais não nos ocorre que possam ser questionados... este ceticismo inicial será mero auto- engano, e não dúvida real; e ninguém que siga o método cartesiano jamais ficará satisfeito enquanto não recuperar formalmente todas aquelas crenças que, formalmente, abandonou. Portanto, é uma preliminar tão inútil..." ${ }^{159}$.

Não podemos partir, no inquérito sobre o mundo, senão de nossas certezas e de nossas dúvidas reais, e apenas a vontade de afastar a dúvida real pode ser 0 motor da pesquisa. Como lemos em "W hat Pragmatism Is?" de 1905, de fato, o único estado de que se pode partir é o estado real no qual se encontra; numa imensa massa de conhecimento já formado do qual não se pode livrar, não há primeiro termo, o conhecimento tem sempre já começado, e não se pode refletir e inferir senão a partir de pensamentos que já estejam lá. Não há tábula rasa - e não se pode pensar a partir de uma intuição que não provenha do objeto - nem dúvida metódica que, desembaraçada dos conhecimentos já adquiridos, nos permita adotar uma primeira certeza.

"Todas as coisas com que você tem quaisquer negócios são suas dúvidas e crenças, com o curso da vida que Ihe impõe novas crenças e lhe dá o poder de duvidar de velhas crenças. Se os termos 'verdade' e 'falsidade' usados por você forem tomados em acepções que sejam definíveis em termos de dúvida e crença e de curso de experiência (tal como, por exemplo, eles o seriam se você definisse 'verdade' como uma crença para a qual tenderia se tendesse indefinidamente para uma fixidez absoluta) muito bem: nesse caso, você só estaria falando da dúvida e crença. Contudo, se por verdade e crença entender algo que não seja de modo algum definível em termos de dúvida e crença, neste caso estará falando de entidades cuja existência você nada pode saber, e que a navalha de Ockham eliminaria de imediato. Os problemas seriam muito simplificados se, em vez de dizer que deseja conhecer a 'Verdade', você dissesse simplesmente que deseja al cançar um estado de crença inatacável pela dúvida"60.

\footnotetext{
57 IBIDEM, 5.371.

58 BOUVERESSE (1987, p. 567 seq.) reconheceu a proximidade da crítica ao cartesianismo em Peirce com o Wittgenstein de Über Gewibheit. Procurei discutir aspectos do pragmatismo e da crítica epistemológica nestes dois autores em SILVA FILHO, 1995, 1998 e, mais detidamente, 1999.

59 PEIRCE, CP 5.265.

60 IBIDEM, 5.416.
} 
Apenas no inquérito real, na emergência de problemas reais (que constringem ao agir) é que a dúvida (e a crença) têm significado. A característica experimental (falibilista e provisória) solicita a busca de crenças justificadas e revisáveis: é a marca exploratória, abdutiva, heurística do inquérito que se impõe, inexoravelmente, como uma regra essencial da filosofia pragmatista ${ }^{61}$. Contra Descartes, deve-se considerar que a dúvida não é mais decisiva que a crença, ou melhor, a dúvida não pode gerar qualquer conhecimento, pois, como vimos, 0 conhecimento depende de um aparato bem formado e crido para ser reconhecido como tal. A crença é mais do que um momento vivenciado pela consciência; ela é "um hábito da mente" ${ }^{62}$ que permite 0 reconhecimento do fluxo contínuo do mundo segundo uma ordem. A dúvida, ao contrário, é uma privação dessa possibilidade: é uma "ausência de hábito". E a pesquisa, qualquer que seja, prática, científica ou filosófica, não é senão um esforço de sair de uma dúvida real para chegar a uma crença. Assim, não há dúvida primeira porque: “... não há absolutamente uma primeira cognição de um objeto mas, sim, que a cognição surge através de um processo contínuo"63. Do mesmo modo, não há valor epistemológico numa dúvida insincera; não há sentido em duvidar, na Filosofia, daquilo que não duvidamos em nossos corações.

No artigo "The Fixation of Belief", Peirce escreve: "A capacidade de traçar inferências é a última das faculdades sobre que adquirimos amplo domínio; é menos um dom natural do que arte de aprendizado longo e difícil [grifo meu]" ${ }^{\prime 4}$. Aprendemos a traçar inferência porque, nas práticas do conhecimento e do raciocínio, nosso objetivo é descobrir, a partir da avaliação do que já sabemos, algo que não sabemos (é um princípio silogístico: um raciocínio congruente é levado a efeito quando nos conduz de premissas verdadeiras à conclusão verdadeira, afastadas outras possibilidades).

Descartes procurara fundar o cogito como aquilo que não pode ser duvidado ele mesmo. A partir deste ponto, procurava erigir um critério de verdade e de evidência das idéias "claras e distintas". Peirce considera que esse critério de evidência se resumiria na seguinte fórmula: tudo isto que eu concebo claramente é verdadeiro. Mas fazer dos indivíduos singulares os juizes absolutos da verdade é algo muito arriscado e improvável para um cientista como Peirce. No sentido pejorativo de "metafísica", cada filósofo procura atingir a um degrau extremo de certeza, mas de uma certeza solipsista, que não é partilha-

\footnotetext{
61 TIERCELIN, 1993b, p. 24.

62 PEIRCE, CP 5.417.

63 IBIDEM, 5.265.

64 IBIDEM, 5.359.
} 
da por ninguém. Na ciência, ao contrário, um acordo pode ser feito entre pesquisadores.

Descartes pensava naquilo que fosse "très clair", mas é incorreto supor que uma idéia isolada possa ser diferente de uma ilusão. Ele professava a dúvida no recurso à memória, e o que sobra é uma vaga idéia indescritível, pois não existe qualquer garantia que permita colocar a "primeira pessoa do singular"65 sob suspeita. Como no tribunal, exemplo recorrente de Peirce, mais do que as evidências e a credibilidade de cada testemunha que fala em nome do "- Eu sei porque eu experimentei", o que importa é o acordo e a convergência de opiniões. Como salienta Apel ${ }^{66}$, o "falibilismo" e o pressuposto do consenso público implicam que a teoria do conhecimento não pode recorrer à evidência privada da consciência como instância última e autárquica da certeza. 0 "Eu penso" é uma petitio principii porque, independente do que eu venha dizer subseqüentemente, esta frase só pode afirmar a si mesma. Não é um princípio-guia, mas a aplicação de um princípio que crê que a palavra "eu" se refere ao seu portador inalienável.

Há uma impossibilidade de se concluir validamente a existência de um eu porque o cogito não é uma idéia clara (uma idéia não pode ser clara, nem se impor a ela mesma como verdadeira, se está isolada) ${ }^{67}$. Numa carta a Lady Welby, lemos que se a verdade é qualquer coisa de público, isto deveria significar que, não uma pessoa, mas o agente intersubjetivo (a pessoa portadora de crença e linguagem) chegaria inevitavelmente a um mesmo e único fundamento para sua conduta, bastando que conduzisse seu inquérito com objetivos sinceros:

“M as, podes dizer, eu estou colocando esta proposição como verdade infalível. Não é isto: esta é uma simples definição. Eu não disse que é infalivelmente verdadeiro que exista um crença à qual uma pessoa alcançaria se conduzir seu inquérito o mais longe possível. Eu disse apenas que é somente isto que eu chamo Verdade. Eu não posso infalivelmente saber se a Verdade existe"68.

A verdade tem esse "caráter público" porque é a concordância de um enunciado ou um conjunto de enunciados com os limites ideais aos quais tende a pesquisa conduzida no interior de uma comunidade de inquérito. A afirmação "holística" de que não há idéias isoladas se deve ao "holismo semiósico", que sustenta que não há signos isolados. Já discutimos isto: do mesmo modo que um signo exige um outro signo que o interprete (seu interpretante), todo pensamento, todo conhecimento ou conceito é, por natureza, provisório. Determinado por

\footnotetext{
65 Cf. DAVIDSON, 1991.

${ }^{66}$ APEL, 1995, p. 111.

${ }^{67}$ CHENU, 1984, p. 147.

68 PEIRCE, 1978, p. 43.
} 
um pensamento anterior, todo pensamento chama um outro pensamento que o interprete. De fato, não há simples paralelismo entre pensamento e signo: os pensamentos são signos - num binômio, pensamento-signo (thought-signs). Neste sentido, não poderia jamais existir uma idéia perfeitamente clara. Uma idéia não pode senão tornar-se clara e mais rica - à medida que se desenvolve nos interpretantes que se revisam e se ampliam em novos sentidos e implicações.

Considerando que o real está inscrito no tecido sígnico que pertence às conquistas de uma comunidade, inquérito é o nome de um processo espiritual que é suscetível de descrição, crítica e correção de um ponto de vista lógico e público. Não há sentido em se comparar nossas crenças e teorias (e as proposições que as exprimem) com um objeto em si ou exterior à representação, e é vão falar da verdade concebida como um acordo entre 0 pensamento e seu objeto. 0 acordo entre crença e real não pode jamais ser estabelecido fora da crença e da interpretação. Por essa razão, a dúvida tem uma função puramente lógica: é um estímulo a indagar até vê-la destruída numa pesquisa em direção à confluência de interpretações:

“... o único objetivo do inquérito é $o$ acordo de opiniões. Podemos pretender que isso não nos basta e que buscamos não apenas uma opinião, mas uma opinião verdadeira. Exponhamos, porém, essa pretensão à prova e ela se revelará sem fundamento, pois, tão logo alcançamos uma crença firme, sentimo-nos satisfeitos por completo, seja essa crença verdadeira ou falsa. E, claro está, nada que se mantenha fora da nossa esfera de conhecimento pode constituir-se, para nós, em objeto, pois só o que afeta o espírito é suscetível de ver-se transformado em motivo de esforço mental [grifos meus]" ${ }^{\prime 9}$.

Esse percurso, apesar do tom relativista, não leva a teses que se confundem com o ceticismo. Barry Stroud ${ }^{70}$ salienta que o principal ingrediente do ceticismo é o fato de que nos confinamos às representações das coisas que, até onde podemos saber, poderiam ter ou não alguma correspondência com a realidade. Estamos, ao menos no âmbito epistemológico, presos à lógica das representações. Qualquer empresa de ir além dela para julgar e dizer se o mundo é, em verdade, como representamos, somente pode ser o resultado de mais representações. Por isso, em Peirce, o nervo se encontra no modo de fixar a crença, ou seja, no modo de estabelecer a ordem das representações e dos juízos. Pois, se é verdade que não podemos nos livrar da lógica das representações, é verdade, do mesmo modo, que podemos enunciar as razões pelas quais afirmamos o que nossas palavras dizem. Quando desposamos uma crença, assim como "percebemos" algo, não temos condições de estar afastados da crença que abraçamos: "Podemos, no máxi-

\footnotetext{
69 IBIDEM, 5.375.

70 STROUD, 1984, p. 45.
} 
mo, sustentar que buscamos uma crença que julguemos verdadeira. Julgamos, contudo, que é verdadeira cada uma de nossas crenças e, assim, a afirmação é mera tautologia" ${ }^{71}$.

- Devemos auspiciar esclarecer a crença. Por isso, falará, em "The Fixation of Belief" de "métodos de fixação das crenças" (o método da tenacidade, 0 método da autoridade, o método a priori e o método da ciência). Deixemos de lado os dois primeiros que pertenceriam, digamos assim, ao senso comum, e estão relacionados ao modo como os homens e mulheres têm se apegado acriticamente a noções de verdade, sem exercer qualquer reflexão: apenas abraçam ao peito ou obedecem, independentemente da força de qualquer prova contrária ${ }^{72}$. Pensemos nos métodos "a priori" e "da ciência". Nessa locução - "método a priori" - há uma referência à tradição filosófica de Platão a Hegel, que teria fundado sua metafísica sob as únicas exigências de conceitos previamente formados por uma racionalidade abstrata e não experimental. Para o "método a priori", os homens poderiam ser conduzidos à mesma conclusão, negando qualquer possibilidade de revisão e de contradição (ou falibilismo).

0 "método da ciência", ao contrário, deve afetar não ao indivíduo, mas a todas as pessoas. Muito embora as formas das pessoas serem afetadas sejam muitas e variadas, devemos auspiciar algumas condições básicas que atinjam a todos. 0 "método da ciência" está ligado, antes de mais nada, a um conceito forte de realidade ${ }^{73}$. Peirce afirma:

"Há coisas Reais, cujas características são inteiramente independentes de nossas opiniões a respeito delas; esses reais afetam nossos sentidos segundo leis regulares, e conquanto nossas sensações sejam tão diversas quanto nossas relações com os objetos, poderemos, valendo-nos das leis da percepção, averiguar, através do raciocínio, como efetiva e verdadeiramente as coisas são; e todo homem, desde que tenha experiência bastante e raciocine suficientemente acerca do assunto, será levado à conclusão única e Verdadeira. A concepção nova que se introduz é a da Realidade.

Cabe perguntar como sei que há Reais [grifos meus]"74.

Uma investigação, obrigatoriamente, deve apontar para algo como coisa real. Ao fazer isso - o método é posto em prática - deve-se eliminar as dúvidas residuais acerca do próprio método, posto que o sentimento que permite 0 surgimento dos métodos de fixação da crença é o de insatisfação diante de proposições conflitantes. Ninguém pode duvidar de que existam reais, pois que, se assim fosse, essa dúvida não

\footnotetext{
71 PEIRCE, CP 5.375.

72 IBIDEM, 5.377-383.

73 Sobre o realismo em Peirce, ver APEL (1986b), ENGEL-TIERCELIN (1986), HOOKWAY (1986) e CHAUVIRÉ (1995).

${ }^{74}$ PEIRCE, CP 5.384.
} 
seria fonte de um inquérito e de perguntas. Há método científico porque buscamos solucionar e explicar o objeto da nossa surpresa e inquietação; todos aqueles que preservarem uma dúvida séria a propósito do assunto deverão ter as condições de examiná-lo.

\section{Epílogo: o homem-mulher-signo ou a derrota do subjetivo}

Negar o caráter fundante do cogito na dúvida hiperbólica, como vimos, estabelece um outro estatuto para o sujeito do conhecimento. 0 nervo dessa solução pragmática da subjetividade ${ }^{75}$ fora determinado pela terceira incapacidade apresentada em "Some Consequences of Four Incapacities": a incapacidade de pensar sem signos. Noutros termos, ela significa que o pensamento é formado de uma rede de estados lógico-psicológicos que são signos ou que têm a função de signo: "thought-sign". Peirce insiste em dizer que isto que é signo são manifestações fenomênicas de nós mesmos, de sorte que, quando pensamos, "nós mesmos, tal que somos neste momento", isto é, na modificação que nos afeta, "somos parecidos como um signo"76. Para Eco, o signo, como estágio de um processo de semiose, é um instrumento por meio do qual o próprio sujeito se constrói e se desconstrói constantemente: "O sujeito é aquilo que os constantes processos de resegmentação do conteúdo permitem que ele seja"77.

"O homem cria a palavra para que signifique expressamente o que ele deseja, $e$ apenas para esse indivíduo particular. Mas, uma vez que o homem só pensa por signos e outros símbolos exteriores, estes poderiam retorquir: 'tudo o que você diz o aprendeu conosco, e sempre precisará de uma palavra como interpretante do seu pensamento'. De fato, homens e palavras educam-se mutuamente; cada aumento de informação humana envolve e é envolvido por um aumento de informação das palavras.

... a palavra ou signo usada pelo homem é [grifo do autor] o próprio homem. Se cada pensamento é um signo e a vida é uma corrente de pensamento, o homem é um signo; o fato de cada pensamento ser um signo exterior prova que o homem é um signo exterior. Quer dizer, o homem e o signo exterior são idênticos [...]. A minha linguagem [...] é a soma de mim próprio; porque o homem é o pensamento [grifo do autor]." 78

0 homem é um signo porque os elementos que constituem sua subjetividade (a emoção, a sensação, o desejo, o juízo, a ação) só podem ser conhe-

\footnotetext{
75 Para uma abordagem mais cuidadosa sobre a idéia de subjetividade em Peirce, ultrapassando os limites estreitos deste artigo, ver COLAPIETRO (1989).

76 PEIRCE, CP 5.283.

77 ECO, 1984, p. 71.

78 PEIRCE, CP 5.313-314.
} 
cidos discursivamente. As dimensões do signo (primeiridade, segundidade e terceiridade) não são estágios cronológicos nem correspondem a fatos ontológicos; na verdade, dizem respeito ao movimento perpétuo - significação e re-significação - do contínuo do mundo (mundo que inclui 0 corpo do homem-signo).

Quando fala daquilo que presumivelmente pertence mais intimamente ao corpo do homem-signo - sensação ou, como prefere Tiercelin ${ }^{79}$, vague de la sensation - está tratando de uma síntese de conhecimentos anteriores e de impressões numerosas mais ou menos complexas, que são, assim, reunidas numa unidade. A sensação é algo de simples, parece que ela não depende de um princípio racional. Complexa, na verdade, é a síntese. Uma sensação é um predicado simples colocado no lugar de um predicado complexo; noutros termos, ela tem a função de uma hipótese.

Antes de mais nada, o homem-signo e o pensamento-signo são termos que se sustentam na doutrina das categorias: nenhum imediato enquanto tal é elemento do pensamento, nem a qualidade pura, nem o puro existente singular. O espírito-mind é um signo se desenvolvendo conforme as leis da inferência, porque na Ciência e na Moral, mas também na Estética, quando adotamos crenças, as nossas palavras aprendidas publicamente com outros homens e mulheres justificam nossa relação com nossos objetos (aqueles que cartesianamente se dariam dentro de nós e só conheceríamos no auto-exame introspectivo). Tudo que pertence ao eu (toda a ontologia interior) é, em primeiro lugar, significado no tecido público da objetividade. A instância da subjetividade (se há algo como isso) só pode ser compreendida nesse tecido: na regra, na crença, na objetividade, no signo. Como veio aparecer em "W hat Pragmatism Is?", lemos:

"... duas coisas muito importantes de que devemos nos certificar e lembrar. A primeira é que uma pessoa não é, em absoluto, um individual. Seus pensamentos são aquilo que ela está 'dizendo de si mesma', ou seja, aquilo que está dizendo ao outro eu que está surgindo para a vida no fluxo do tempo. Quando raciocinamos, é esse eu crítico que estamos tentando persuadir; e todo pensamento, seja qual for, é um signo, e é fundamentalmente da natureza da linguagem. A segunda coisa a lembrar é que o círculo da sociedade de alguém [...] é uma espécie de pessoa frouxamente compactada [...]. São estas duas coisas apenas que tornam possível ao leitor [...] distinguir entre a verdade absoluta e aquilo de que o leitor não duvida"[grifos meus] ${ }^{80}$.

Ora, o pragmatismo tem se sustentado, primeiramente, sobre a recusa sistemática da "experiência pura", da "consciência pura", da "subjetividade pura", sem ter, em Peirce, recusado o sentido positivo da experiência, da realidade e da verdade para cair no relativismo e no

\footnotetext{
79 TIERCELIN, 1993b, p. 119 seq.

80 PEIRCE, CP 5.421.
} 
ceticismo (mesmo Rorty recusa o ceticismo e o relativismo) ${ }^{81}$. Com Peirce, despedir-se do "espírito do cartesianismo" não pode significar um abandono da interrogação epistemológica, ao contrário, significa reescrevêla na letra do significado (Davidson faz alusão a uma epistemologia no espelho do significado82). Uma concepção (ou uma crítica) de pragmaticistas da subjetividade e do conhecimento parece ser um bom caminho para prosseguir a investigação filosófica... principalmente se considerarmos os rumos tomados pelo pragmatismo depois de Quine, Putnam, Rorty, Goodman e Davidson (mas essa já é outra história).

\section{Referências bibliográficas}

ALM EDER, Robert. The Philosophy of Charles S. Peirce: A Critical Introduction. Totowa: Rowman and Littlefield, 1980.

APEL, Karl-Otto. Le problème de l'évidence phénoménologique à la lumière d'une sémiotique transcendantale. Trad. do alemão por Jacques Poulain. Critique, tome XLII, n. 464-465 (1986a) 79-113.

. La métaphysique de l'évolution. Trad. Claudine Engel-Tiercelin. Philosophie, n. 10 (1986b) 25-47.

- Teoría de la verdad y ética del discurso. Trad. do alemão por Norberto Smilg. Barcelona: Paidós, 1995.

BICCA, L. Racionalidade moderna e subjetividade. São Paulo: Loyola, 1997.

BOUVERESSE, Jacques. Le mythe de l'intériorité: expérience, signification et langage privé chez Wittgenstein. Paris: Minuit, ${ }^{2} 1987$.

CHAUVIRÉ, Christiane. Peirce, le langage et l'action: sur la théorie peircienne de l'assertion. Les études philosophiques, n. 1 (1979) 3-17.

$\overline{3}(1981)$ 257-278.

Vérifier ou falsifier: de Peirce a Popper. Les études philosophiques, $\mathrm{n}$.

Peirce et la signification. Paris: PUF, 1995.

CHENU, Joseph. Une philosophie de la discursivité radicale: essai introductif. In PEIRCE, Charles S. Textes anticartésiens. Paris: Aubier, 1984.

COLAPIETRO, Vincent. Peirce's Approach to the Self: A Semiotic Perspective on Human Subjectivity. Albany: State University of New York Press, 1989.

COM ETTI, Jean-Pierre. Le pragmatisme: de Peirce a Rorty. In MEYER, Michel. La Philosophie anglo-saxonne. Paris :PUF, 1994.

DAVIDSON, Donald. Thought and Talk. In . Inquiries into Truth and Interpretation, New York: Oxford University Press, 1984. 155-170.

${ }^{81}$ RORTY, 1991; 1998.

82 Cf. DAVIDSON, 1984, p. 169. 
. Epistemology Externalized. Dialetica, vol. 45, n. 2-3 (1991) 191-202.

DELEDALLE, Gerard. Théorie et pratique du signe: introduction à la sémiotique de Charles S. Peirce. Paris: Payot, 1979.

- Lire Peirce aujourd'hui. Bruxelles: Boeck-Wesmael, 1990.

DESCARTES, René. Les principes de la philosophie (première partie). Paris: Vrin, 1950.

- Meditações sobre a filosofia primeira. Trad. do latim por Gustavo de Fraga. Coimbra: Almedina, 1988.

ECO, Umberto. Segno. Milano: ISEDI, 1973.

. Semiotica e filosofia del linguaggio. Torino: Einaudi, 1984.

ENGEL-TIERCELIN, Claudine. Le vague est-il réel? Sur le réalisme de Peirce. Philosophie, n. 10 (1986) 69-96.

FREEMAN, Eugene (ed.). The Relevance of Charles S. Peirce. LaSalle: Monist Library of Philosophers, 1983.

GALLIE, W. B. Introduzione a Charles S. Peirce e il pragmatismo. Trad. do inglês por Roberto Tettucci. Firenze: C/E Giunti, 1970.

GUEROULT, Martial. Descartes selon I'ordre des raisons (I): I'âme et Dieu. Paris: Aubier, 1953.

HAUSMAN, Carl R. Charles S. Peirce's Philosophy. Cambridge: Cambridge University Press, 1993.

HOOKWAY, Christopher. Peirce, le fondationalisme et la justification des connaissances. Trad. Claudine Engel-Tiercelin. Philosophie, n. 10 (1986) 48-67. Peirce. London/ New York: Routledge, 1992.

KETNER, Kenneth L. His Glassy Essence: An Autobiography of Charles Sanders Peirce. Nashville/ London: Vanderbilt University Press, 1998.

MERRELL, Floyd. Peirce's Semiotics Now. Toronto: Canadian Scholars Press, 1995.

Toronto Press, 1997. Zulia, 1998.

Introducción a la semiótica de C. S. Peirce. Maracaibo: Universidad del

M IÉVILLE, Denis (éd.). Charles Sanders Peirce: apports récents et perspectives en épistémologie, sémiologie, logique (actes du colloque, Neuchâtel 16-17 avril 1993). Travaux du Centre de Recherches Sémiologiques, n. 62, avril 1994.

MOUNCE, H. O. The Two Pragmatisms. from Peirce to Rorty. London: Routledge \& Kegan Paul, 1997.

MURPHEY, Murray G. The Development of Peirce's Philosophy. Indianapolis/ Cambridge: Hackett Publishing, 1993.

MURPHY, John. O pragmatismo: de Peirce a Davidson. Trad. do inglês por Jorge Costa. Lisboa: Asa, 1993.

PEIRCE, Charles S. Collected Papers of Charles S. Peirce. Vols. 1-6. Ed. Hartshorne and P. W eiss. Cambridge: Harvard University Press, 1931-5. 
. Collected Papers of Charles S. Peirce. Vols. 7-8. Ed. A. W. Burks. Cambridge: Harvard University Press, 1958.

_. Semiótica. Trad. José T. Coelho. São Paulo: Perspectiva, 1977.

$\overline{1978 .}$

. Écrits sur le signe. Trad. do inglês por Gérard Deledalle. Paris: Seuil,

Writings of Charles S. Peirce: A Chronological Edition. Vols. 1-4. Ed.

Max Fisch. Bloomington: Indiana University Press, 1982-6

- Textes anticartésiens. Trad. Joseph Chenu. Paris: Aubier, 1984.

. The Essential Peirce: Selected Philosophical W ritings. Volume 2 (1893-

1913). Bloomington/Indianapolis: Indiana University Press, 1998.

POULAIN, Jacques. Le partage de I'héritage anticartésien de Peirce: Davidson, Putnam er Rorty. Rue Descartes, n. 5-6 (1992) 23-52.

RORTY, Richard. Objectivity, Relativism, and Truth: Philosophical Papers, vol.

1. Cambridge: Cambridge University Press, 1991.

- Truth and Progress: Philosophical Papers, vol. 3. Cambridge: Cambridge University Press, 1998.

SARTRE, Jean-Paul. L'imaginaire: Psychologie phénoménologique de l'imagination. Paris: Gallimard, 1986.

SILVA FILHO, Waldomiro José da. Discursos da ação: Primeiras notas para uma investigação sobre 'significação' no pragmatismo. In VVAA. O sentido e a época. Salvador: UFBA, 1995.

. El antiemilio. Cuadernos de Rosario, vol. 1, n. 4 (1998) 51-71.

. Um dogma para o pragmatismo: porque não são os significados privados. Salvador: Tese de doutorado, 1999.

STROUD, Barry. The Significance of Philosophical Scepticism. Oxford: Oxford University Press, 1984.

TIERCELIN, Claudine. C. S. Peirce et le pragmatisme. Paris: PUF, 1993a.

. La pensée signe: études sur C. S. Peirce. Nîmes: Chambon, 1993b.

WIENER, Philip - F. H. YOUNG (eds.). Studies in the Philosophy of Charles S. Peirce. Cambrigde: Harvard Univeristy Press, 1952.

Endereço do autor:

Rua Renato Mendonça, 317/1404 - Brotas

40.285-440 Salvador - BA 